\title{
FOREST MANAGEMENT IN DANGILA WOREDA, ETHIOPIA: BIRD EYES VIEW ON AGAMENGI COMMUNITY FOREST
}

\section{Gedifew Sewenet YIGZA W}

Bahir Dar University, Department of Governance and Development Studies, ,Ethiopia, sgedifew2010@gmail.com

Article history:
Accepted 25 March 2019
Available online 30 April 2019
Keywords:
Causes;
Degradation;
Fuel Wood;
Resource;
Status

\begin{abstract}
A b s t r a c t
This study highlights the overall current performance of Agamengi forest management. Descriptive survey method was employed in this study. A total of 182 respondents from 2183 households were selected through simple random sampling technique. Questionnaire, key informant interview and focus group discussions were mainly employed as data collection tools in this study. This desirable sample size was determined by using Yamane's statistical sample size determination formula. The major findings of this study revealed that the status and management of Agamengi forest in the last 30 years was much dense and there was proper management of the forest. However, the current forest status is degraded and the forest management is poor mainly due to rapid population pressure, high demand for fuel-wood, farmland expansion, charcoal making and inadequate implementation of forest laws. This study recommends that all concerned stakeholders should work together to keep and maintain the quality of the Agemengi forest through applying re-afforestation and afforestation methods.
\end{abstract}

\section{Introduction}

Development for the most part bases on the utilization and management of environmental resources, like natural forests. Globally, forest management with an emphasis on participatory approaches and local benefits has become a phenomenon around the world (Agrawal \& Gupta, 2005; Nilsson, 2005).

According to FAO (2009), Ethiopia loses about 141,000 hectares of forest each year. The main agents of deforestation in Ethiopia include agricultural expansion, the inappropriateness of land-use patterns, the underlying social forces, overgrazing, consumption of firewood and charcoal, fodder collection and forest fire. Besides these, poverty and rapid population growth are also seen as the main causes of forest depletion. Besides these, Girma (2005) noted that forest fires, encroachment of forest reserves, livestock grazing, and timber and firewood collection by the local people have also significantly contributed to deforestation.

Experiences made in Ethiopia have also shown that participatory forest management approaches can play a key role in reversing the ongoing process of forest degradation. However, Mulugeta and Melaku (2008) noted that the current trend of natural resource exploitation in Ethiopia is unsustainable and it has led to land degradation, loss of fresh water bodies and decline of biodiversity. Hence, the forestry sector is facing the challenge of balancing utilization with conservation which requires appropriate forest policy and laws; strong and stable institutional set up, and strong forest related research backing. The status, management and economic benefits of the forest is not so far being studied. Therefore, the overall objective of this study is to give bird eyes view on the management of Agamengi forest in Dangila woreda, Ethiopia.

\section{Methods}

A descriptive survey research method was applied to have rich and clear information on forest management and conservation efforts of the government and the involvement of adjacent community. In this study, transect walk, key informant interview, focus group discussion and questionnaire survey as primary data collection techniques were mainly used.

Concerning respondent selection, based up on the degree of proximity to the Agamengi forest resource, a total of 182 desirable sample size from 2183 households using Yamane 
(1967) statistical sample size formula was determined and simple random sampling method was used for selecting these respondents in this study. Finally, the quantitative data were cleaned, coded and entered into Microsoft excel software application to generate figures. The quantitative data were analyzed using simple descriptive analytical techniques, mainly percentages. Data collected through open-ended items; responses of key informant interviewees and focus group discussion were analyzed through narration.

\section{Major Findings}

\subsection{The Past Status and Management of Agamengi Forest}

The figure 1 below clearly shows the status and proper management of the Agamengi forest resource in the last 30 years.

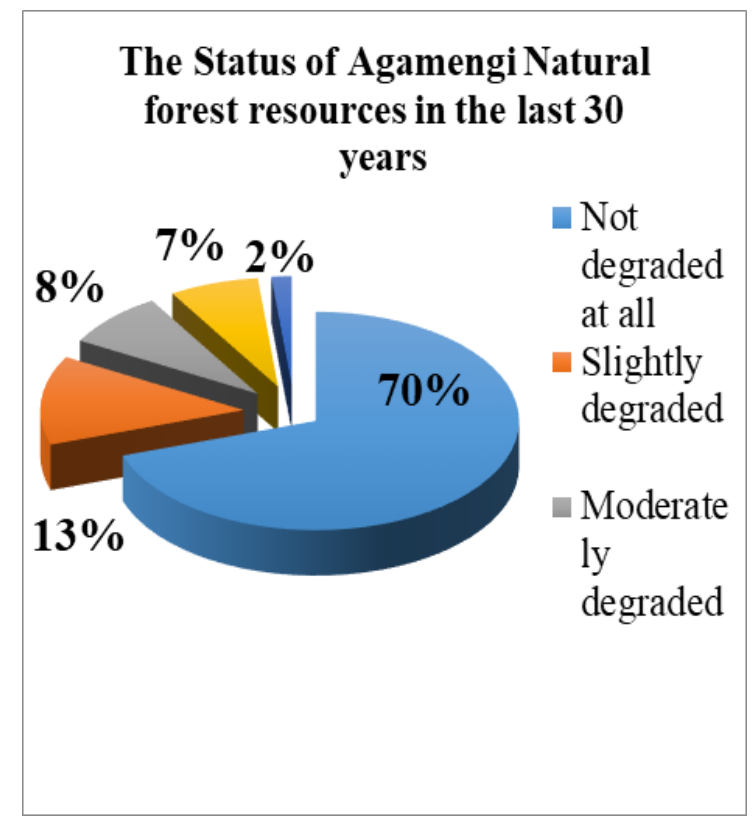

Figure 1. Past status of Agamengi forest

As it has shown in figure $1,70 \%$ of the sample farmers responded that the status and management of Agamengi forest in the last 30 years was much dense and the people were responsible to manage the forest appropriately. Moreover, these respondents agreed that the forest land coverage in the last thirty years was in an excellent condition due to good management of the forest by the adjacent community.

\subsection{Current Forest Coverage and Management status}

Concerning the current forest coverage, majority respondents perceived that the current forest status is excessively degraded and the forest management is poor due to population pressure and high demand for fuel wood.

The key-informant interview held with model farmers shows that;

The status of the Agamengi forest have been under tremendous pressure from an increasing human population and their ever growing demands for shelter, land for cultivation and demand for fuel wood, timber and other forest products necessary for the livelihood. Besides this, the result revealed that the local communities had no awareness regarding the sustainable use of forest resource. They were only applying their indigenous knowledge for forest protection rather than integrating their knowledge with scientific way which was being important to ensure environmental sustainability.

Yohannes, a model farmer, who had lived over 50 years around the forest, narrated that:

The Agamengi forest was the main source of food for us in the last 30 years. It was very much dense forest during the past regimes because the then government was very much sensitive in protecting and managing forest resources. The forests were mainly state forests. Agamengi forest was the home of bio-diversity in the past century. There were so many wild animals like, tiger, lion, Gazelle...etc. and indigenous dominant tree species in the forest in the last 30 years; however, these fauna and flora are almost disappeared today. The forest recently becomes the home of human population and livestock due to fast population growth, livestock rising, farmland expansion and demand for fuel-wood. It was observed that some farms were close to the forest and even shares border with the forest too.

Similarly, Focus group discussions (FGDs) held with eight local development committee members concerning the post 1990's forest status revealed that:

There were no guards hired by the government or by the community so as to 
improve the sustainability of Agamengi forest resource. As a result, there was free roaming of livestock, cutting of trees for sale and charcoal making inside the forest. Moreover, the government did not give full legitimacy practically to the communities to control deforestation. In theory, the forest is assumed to be in the hands of the community but still there is strong government control.

From this one can infer that the Agamengi forest is not currently managed properly and the management system is very poor. This poor status of forest management led to forest degradation and exploitation. Therefore, the concerned bodies and other stakeholders should contribute their efforts to rehabilitate the forest for sustainable use.

Majority of the respondents ranked carelessness of forestry experts or lack of forest experts' work commitment towards sustainable forest management as the primary reason for poor conservation and management of Agamengi forest, followed by lack of community awareness $(21 \%)$. Poor implementation of the forest laws is ranked third. Lack of skills by local development agents and absence of forest guards are also the additional reasons for the current poor management of the forest.

\subsection{Perceived Causes of Agamengi Forest Destruction}

This study identified greater demand for charcoal making, fuelwood collection, greater number of livestock, farm land expansion and population growth, unintentional bush burning, lack of community awareness, demand for house construction and inadequate forest legislation as major perceived causes of forest degradation.

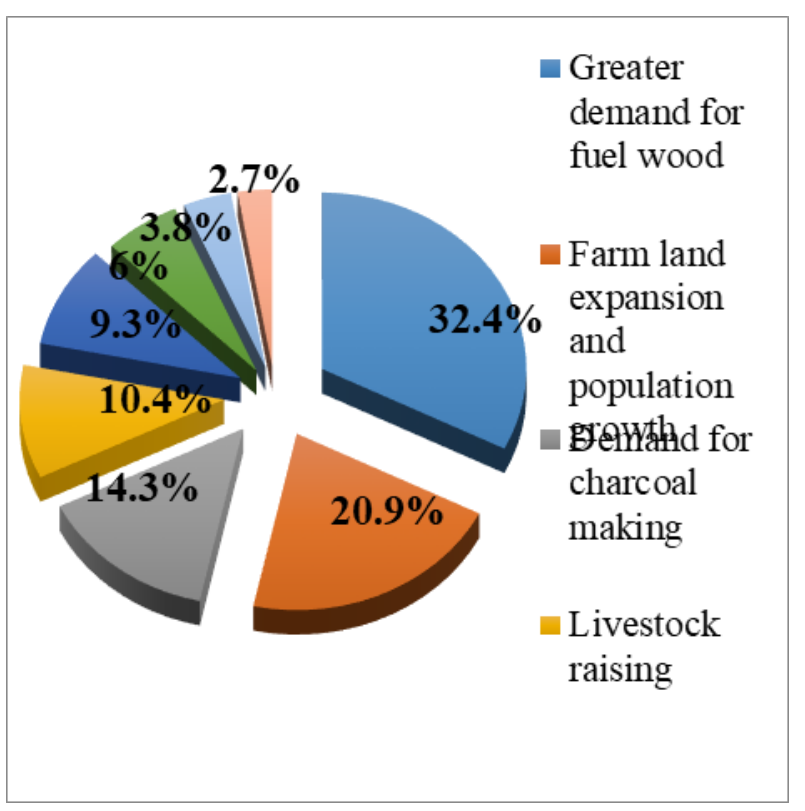

Figure2. Perceived major causes of Agamengi forest degradation

As it has shown in figure 2, Fuel wood is the most common and major household energy source for home based activities. Because of lack of modern electric energy supply and bio-gas, majority of the households are dependent on fuel wood for household cooking. From these stand point, about 32.4 percent replied the greater demand of the people for fuel wood as the main perceived cause of Agamengi forest degradation.

On the other side, about 20.9 percent of respondents identified expansion of agricultural land and population pressure as the $2^{\text {nd }}$ major cause of forest destruction. Moreover, demand for charcoal making, livestock rising, lack of community awareness, inadequate forest legislation, cutting trees for house construction and unintentional bush firing as additional causes of forest quality decline.

One key informant forest management expert narrated about inadequacy of forest legislation as a cause of forest destruction:

There were strong government forest laws and legislations formulated for ensuring sustainable forest management and to assure active community participation in forest conservation. However, there is discrepancy between formulated laws and their actual implementations. The existing laws are like; "'toothless dog." Local communities have no room to participate in forest management. There is still centralized forest management system. As a result, inadequate forest laws, legislations and inadequate land policies 
are mentioned as perceived causes of forest destruction.

Besides, key informant interview held with local community development and forest management committee also mentioned scarcity of land, poor economic conditions and rapid population growth as other causes of forest destruction. They also added that free roaming of livestock into the forest caused great damage to the forest by fueling soil erosion since the forest is mountainous.

\section{Conclusion}

The study revealed that the status and management of Agamengi forest in the last 30 years was much dense and the people were responsible to manage it appropriately. However, the current forest status is much degraded and the forest management is poor. This poor status of forest management led to forest degradation and exploitation. High population pressure, greater demand for fuel wood, inadequate implementation of forest laws, cutting of trees for sale and charcoal making inside the forest were identified as causes of forest degradation. Finally, this may cause the climate change and lose of biodiversity. Hence, the government and the community should work together to improve forest sustainability and full legitimacy should be given to the communities.

\section{References}

1. Agrawal A. \& Gupta K. (2005). Decentralization and Participation: The governance of Common Pool Resources in Nepal's Terai. World Development, 33 (7), 1101-1114.

2. Aklilu A., Feyera S. \& Tsegaye B. (2004). Impact of Participatory Forest Management Practice in AdabaDodola Forest Priority Area of Oromia, Ethiopia. Ethiopian Journal of Natural Resource, 6: 89-109.

3. Food and Agricultural Organization (FAO) (2009). State of the World's Forests. Rome: FAO.

4. Girma A. (2005). Rehabilitation and sustainable use of degraded community forests in the Bale Mountains of Ethiopia. Inaugural Dissertation. Albert-Ludwigs-University, Freiburg im Breisgau, Germany.

5. Mulugeta L. \& Melaku B. (2008). Participatory Forest Management Best Practices, Lessons Learnt and Challenges Encountered: The Ethiopian and Tanzanian Experience Farm-Africa/SOS-Sahel, March 2008. Africa/SOS-Sahel.

6. Nilsson, S. (2005). Experiences of policy reforms of the forest sector in transition and other countries. Forest Policy and Economics 7, 831-847. 